\title{
UNA NUEVA ÓPTICA SOBRE EL CONTROL DE CONVENCIONALIDAD EN ARGENTINA. COMENTARIOS A LA RESOLUCIÓN DE LA CORTE SUPREMA DE LA NACIÓN EN EL ASUNTO MINISTERIO DE RELACIONES EXTERIORES Y CULTO'
}

\begin{abstract}
A new view on conventional control in Argentina. Comments on the resolution of the Argentina's Supreme Court in the case Ministry of Foreign Affairs and Worship
\end{abstract}

\author{
GONZALO GABRIEL CARRANZA² \\ Universidad Autónoma de Madrid \\ gonzalo.carranza@vam.es
}

Cómo citar/Citation

Carranza, G. G. (2017).

Una nueva óptica sobre el control de convencionalidad en Argentina.

Comentarios a la resolución de la Corte Suprema de la nación en el asunto Ministerio de Relaciones Exteriores y Culto.

Anuario Iberoamericano de Justicia Constitucional, 21, 161-185.

doi: https://doi.org/10.18042/cepc/aijc.21.07

\footnotetext{
1 Este trabajo se enmarca en el proyecto de investigación del Ministerio de Economía y Competitividad de España (DER2016-78391-P) sobre «El control de la ley: constitucional, comunitario y convencional», cuyos investigadores principales son César Aguado Renedo y Antonio López Castillo.

2 Abogado, egresado con mención sobresaliente por la Universidad Nacional de Córdoba (Argentina); máster en Derecho Constitucional por el Centro de Estudios Políticos y Constitucionales y la Universidad Internacional Menéndez Pelayo; doctorando en Derecho, Gobierno y Políticas Públicas por la Universidad Autónoma de Madrid, donde actualmente es investigador y profesor del Área de Derecho Constitucional. Ha cumplido funciones de letrado por oposición en el fuero Contencioso Administrativo del Poder Judicial de la provincia de Córdoba y ha sido profesor e investigador en la Facultad de Derecho y la Facultad de Ciencias Económicas de la Universidad Nacional de Córdoba y la Universidad Blas Pascal.
} 


\section{Resumen}

La resolución de la Corte Suprema argentina en el caso Ministerio de Relaciones Exteriores y Culto s/ informe sentencia dictada en el caso "Fontevecchia y D'Amico vs. Argentina" por la Corte Interamericana de Derecho Humanos ha significado un cambio sustancial en la forma en que se desarrolla el control de convencionalidad en el país más austral del mundo. Su pronunciamiento, en el marco de una nueva composición del máximo tribunal, vino a quebrar la tradicional forma de control desarrollada hasta el momento.

En el presente trabajo se tratará de analizar el contenido de la decisión, precisando — desde el estudio de cada voto—, cuál es el efecto que puede irradiar hacia el futuro, prestando atención a las doctrinas reseñadas por la Corte: el margen de apreciación nacional y el diálogo entre tribunales.

\section{Palabras clave}

Corte Suprema argentina; control de convencionalidad; margen de apreciación nacional; diálogo entre tribunales.

\section{Abstract}

The resolution of the Supreme Court of Argentina in the case Ministerio de Relaciones Exteriores y Culto s/ informe sentencia dictada en el caso "Fontevecchia y D’Amico vs. Argentina" por la Corte Interamericana de Derecho Humanos has meant a substantial change in the way in which the control of conventionality develops in the southernmost country in the world. Its pronouncement, within the framework of a new composition of the maximum court, came to break the traditional form of control developed until the moment. This paper will analyze the content of the decision, specifying, from the study of each vote, the effects that can radiate towards the future, paying attention to the doctrines outlined by the Court: the national margin of appreciation and dialogue between courts.

\section{Keywords}

Supreme Court of Argentina; conventional control; national appreciation margin; dialogue between Courts. 


\section{SUMARIO}

I. INTRODUCCIÓN. II. APROXIMACIÓN CAUSAL. III. LA DENUNCIA DE FALTA DE PROCESO. IV. EL CONTENIDO SUSTANCIAL SUBYACENTE A LA DECISIÓN DE LA CORTE: 1. Apreciaciones iniciales: simpleza y trascendencia. 2. El contenido esencial. 3. La subsidiaridad y la doctrina de la "cuarta instancia»: el camino al espejo procesal. 4. La extralimitación de la CIDH. 5. La introducción de la doctrina del margen de apreciación nacional. 6. El voto particular y el diálogo entre tribunales. 7. El voto en disidencia. V. CONCLUSIONES. BIBLIOGRAFía.

\section{INTRODUCCIÓN}

Comentar una decisión de un órgano judicial implica tratar de desmenuzar su contenido, analizar los supuestos de hecho que le dieron vida y tratar de enmarcar sus pronunciamientos en el ordenamiento jurídico en el que se inserta.

El hecho de examinar una resolución del máximo tribunal de la República Argentina implica, ya de sí, un desafío. Esto, por cuanto es el mayor intérprete del bloque de constitucionalidad y el depositario de la última palabra del derecho aplicable. Si bien se puede estar o no de acuerdo con lo que este diga, lo importante es recordar que se está frente a quien tiene la autoridad legítima para interpretar la letra y contenido de las normas de aquel país.

Precisamente, el comentario a lo resuelto por la Corte Suprema de Justicia de la Nación (en adelante, y alternativamente, CSJN o Corte) en el asunto Ministerio de Relaciones Exteriores y Culto s/ informe sentencia dictada en el caso "Fontevecchia y D'Amico vs. Argentina» por la Corte Interamericana de Derecho Humanos ${ }^{3}$ implica un noble duelo. Esto es así, por cuanto mucho de lo que la resolución contiene se dirige a descubrir quién tiene la última palabra interpretativa y aplicativa del derecho en el Estado más austral del mundo, cuando existen asuntos nacionales que han llegado a la Corte Interamericana y que han sido resueltos en su contra.

A continuación, se realizarán una serie de comentarios a la decisión de la Corte, no solo a la luz de sus dichos, sino también de la jurisprudencia nacional

3 Véase Fallos 340: 50, resuelto el 14/02/2017. 
e interamericana. Junto a ello, se analizarán distintas posiciones que la doctrina ha tomado frente al caso. Además, se tratará de sentar postura frente al nuevo escenario derivado de la mentada decisión, que ha venido a cambiar varios paradigmas que parecían ser, hasta ahora, inmutables.

\section{APROXIMACIÓN CAUSAL}

No es posible analizar el contenido de los fundamentos jurídicos del asunto tratado por la Corte Suprema sin entender, prima facie, cuáles fueron los hechos - y la secuencia de resoluciones- que la llevaron a adentrarse en el caso.

El 25 de septiembre de $2001^{4}$, el máximo tribunal argentino confirmó la sentencia de la Sala «H» de la Cámara Nacional de Apelaciones en lo Civil que había hecho lugar a la demanda de daños y perjuicios promovida por el expresidente de la nación, D. Carlos Saúl Menem, contra Editorial Perfil S.A., y los periodistas D. Jorge Fontevecchia y D. Héctor D’Amico.

Básicamente, la Corte sostuvo que la difusión de ciertas noticias vinculadas a la presunta existencia de un hijo no reconocido del expresidente había lesionado en forma ilegítima su derecho a la intimidad. Fundó su decisión en que aquel derecho se encuentra tutelado por el art. 19 de la Constitución Nacional y por los arts. 17 , párrafos $1 .^{\circ}$ y $2 .^{\circ}$ del Pacto Internacional de Derechos Civiles y Políticos; y 11 , párrafos $2 .^{\circ}$ y $3 .^{\circ}$, de la Convención Americana sobre Derechos Humanos (en adelante, y alternativamente, $\mathrm{CADH}$ - entre otras normas-, y confirmó la condena pecuniaria dispuesta por la Cámara, reduciendo los montos inicialmente impuestos.

Los hechos que llevaron a que se dictase la sentencia de apelación -y a que la Corte la confirmase-, se cimentaron en la difusión en el semanario Noticias $^{5}$ de dichos e imágenes que comprometían al expresidente en su faz íntima, ya que ponían de relieve algunas cuestiones que corresponden al ámbito familiar y que, además, involucraban a menores.

En aquel momento, la Corte dijo:

Que [...] tanto la difusión de cuestiones familiares íntimas por medio de la palabra escrita como la publicación de imágenes fotográficas -en todo caso no autorizadas por

4 Véase Fallos 324: 2895 - CSJN: Menem, Carlos Saúl vs. Editorial Perfil S.A. y otros s/ daños y perjuicios - sumario, resuelto el 25/09/2001.

5 La revista Noticias, es un semanario argentino, fundado en 1989. Es una revista de análisis político de alcance nacional, perteneciente a la Editorial Perfil S.A. 
el actor en el tiempo y en el contexto en que fueron usadas por el medio de prensasobre presuntos vínculos familiares y sobre el estado anímico de su ex cónyuge en relación a tales lazos, configura una intrusión en la zona de reserva del sujeto no justificada por intereses superiores de la comunidad. Máxime cuando se han incorporado imágenes y nombres de menores, con exposición sin prudencia profesional de cuestiones atinentes a la filiación de estos niños, con mortificación espiritual no solo del hombre en cuanto tal sino en su relación con ellos, conducta que revela el carácter arbitrario de la injerencia en la esfera de intimidad del actor, no justificada por el debate vigoroso de las ideas sobre los asuntos de interés público ni por la transparencia que debe tener la actuación del hombre público en el ejercicio de sus altas responsabilidades ${ }^{6}$.

Una vez firme la sentencia, y habiéndose cumplido la reparación económica que se ordenaba, el 15 de noviembre de 2001, D. Jorge Fontevecchia, D. Héctor D’Amico y D. Horacio Verbitsky (en representación de la Asociación Periodistas), elevaron el caso ante la Corte Interamericana de Derechos Humanos (en adelante, y alternativamente, CIDH), al sostener que se había vulnerado el derecho a la libertad de pensamiento y expresión (tutelado en el art. 13 de la $\mathrm{CADH}^{7}$ ), solicitando que se declarase la responsabilidad internacional del Estado argentino en este caso.

El 29 de noviembre de 2011, la Corte Interamericana determinó la responsabilidad internacional de Argentina, considerando que se había violado el derecho sostenido por los recurrentes. Por ello, se buscó que el Estado argentino reparase el daño infringido, al ser esto una consecuencia de la responsabilidad internacional que sobre él recae (Bazán, 2015: 63).

En aquella oportunidad, determinó que la sentencia era per se una forma de reparación, pero, además, dispuso otra serie de medidas ${ }^{8}$, que se transcriben a continuación:

El Estado debe dejar sin efecto la condena civil impuesta a los señores Jorge Fontevecchia y Héctor D’Amico así como todas sus consecuencias, en el plazo de un año contado a partir de la notificación de la presente sentencia, en los términos del

6 Véase Fallos 324: 2895 - CSJN: Menem, Carlos Saúl vs. Editorial Perfil S.A. y otros s/ daños y perjuicios_sumario, resuelto el 25/09/2001, considerando $16 .^{\circ}$.

7 Digno es recordar que la reforma constitucional de 1994 incorporó a su texto — por medio del art. 75 inc. 22-, diversos instrumentos internacionales de protección de los derechos humanos, a los que se les otorgó jerarquía constitucional, integrando el bloque de constitucionalidad. Entre ellos, se encontró la $\mathrm{CADH}$.

8 Como bien se ha señalado, «el esquema interamericano recepta una amplitud considerablemente mayor en punto a su radio de acción y a la gama de posibilidades de articulación de soluciones a su alcance en materia de reparaciones» (Bazán, 2015: 30). 
párrafo 105 de la misma. El Estado debe realizar las publicaciones dispuestas en la presente sentencia, de conformidad con lo establecido en el párrafo 108 de la misma. El Estado debe entregar los montos referidos en los párrafos 105, 128 y 129 de la presente Sentencia, dentro del plazo de un año contado a partir de su notificación y conforme a las modalidades especificadas en los párrafos 131 a 136 de este fallo?.

Junto a ello, determinó una obligación para el propio órgano, al establecer que:

La Corte supervisará el cumplimiento íntegro de esta sentencia, en ejercicio de sus atribuciones y en cumplimiento de sus deberes conforme a la Convención Americana, y dará por concluido el presente caso una vez que el Estado haya dado cabal cumplimiento a lo dispuesto en la misma. El Estado deberá, dentro del plazo de un año contado a partir de la notificación de esta sentencia, rendir a la Corte un informe sobre las medidas adoptadas para cumplir con la misma ${ }^{10}$.

Básicamente, puede resumirse la parte resolutiva en tres grandes obligaciones:

A) que Argentina debe dejar sin efecto la condena civil impuesta a los recurrentes;

B) la necesidad de dar público conocimiento y difusión de un resumen de la sentencia de la Corte Suprema y la publicación en su totalidad de la de la CIDH, y

C) la obligación del país de entregar las sumas de dinero reconocidas en el fallo (reintegro de los montos de condena de la CSJN), y los que se indican como reparadores en sede internacional (daño material y gastos causídicos internos e internacionales).

Lo dispuesto por la CIDH en el punto «B» fue cumplido por la Corte argentina, mediante la publicación en el portal del Centro de Información Judicial y la página de jurisprudencia de esta ${ }^{11}$.

En relación al punto «C», la Corte indicó que: «[...] las obligaciones allí impuestas se encuentran fuera del alcance de las presentes actuaciones, toda vez que —en esta instancia- no resulta necesaria la intervención judicial

9 Véase caso Fontevecchia y D'Amico vs. Argentina, CIDH, 29/11/2011.

10 Id.

11 De hecho, se puede consultar en la sentencia el link incorporado a fs. 49: http:// sjconsulta.csjn.gov.ar/sjconsulta/documentos/verUnicoDocumentoLink.html?idAnalisis=509297 (consultado el 19/06/2017). 
para que el Estado argentino proceda voluntariamente a su cumplimiento, de acuerdo con la distribución constitucional de competencias entre los distintos poderes del Estado» ${ }^{12}$.

Por último, en relación al punto «A», indica que la Dirección General de Derechos Humanos del Ministerio de Relaciones Exteriores y Culto de la nación, remitió a la Corte un oficio por el que se hacía saber el pedido formulado por la Secretaría de Derechos Humanos de la nación para que el Tribunal cumpla —en lo que corresponda y de conformidad a sus competencias—, la decisión de la CIDH.

La procuradora general de la nación ${ }^{13}$, Dña. Alejandra Gils Carbó, presentó el dictamen requerido por ley en relación al asunto, por el cual consideró, que:

[...] en ejercicio de sus atribuciones y en virtud de las obligaciones que dimanan de la Convención Americana sobre Derechos Humanos (arts. 1, 2 y 68, inc. 1), la Corte Suprema debe dejar sin efecto su fallo dictado a fs. 367/388 de la causa «Menem, Carlos Saúl c/Editorial Perfil S.A. y otros s/ daños y perjuicios» (exp. No 117.391/95). Además, debe revocar el pronunciamiento de la Cámara Nacional de Apelaciones en lo Civil, rechazando la demanda incoada por los fundamentos de la sentencia del tribunal internacional ${ }^{14}$.

El fundamento por el cual llega a su conclusión se basa — sobre todoen el art. 68 inc. 1, de la Convención Americana sobre Derechos Humanos

12 Véase Fallos 340: 50 - CSJN: Ministerio de Relaciones Exteriores y Culto s/ informe sentencia dictada en el caso «Fontevecchia y D’Amico vs. Argentina» por la Corte Interamericana de Derecho Humanos, resuelto el 14/02/2017, considerando 4. ${ }^{\circ}$.

13 Cabe destacar que la figura de «Procurador General de la Nación» está determinada en el art. 120 de la Constitución Nacional, que señala: «El Ministerio Público es un órgano independiente con autonomía funcional y autarquía financiera que tiene por función promover la actuación de la justicia en defensa de la legalidad de los intereses generales de la sociedad en coordinación con las demás autoridades de la República. Está integrado por un procurador general de la Nación y un defensor general de la Nación y los demás miembros que la ley establezca (...)».

Este funcionario tiene por cometido ser el jefe de todos los fiscales que acuden ante tribunales de la nación y, además, es el fiscal ante la Corte Suprema de Justicia de la Nación quien, antes de entrar a resolver un caso, debe oír necesariamente su dictamen.

14 Véase Fallos 340: 50 - Dictamen de la procuradora general de la nación en el asunto Ministerio de Relaciones Exteriores y Culto s/ informe sentencia dictada en el caso «Fontevecchia y D’Amico vs. Argentina» por la Corte Interamericana de Derecho Humanos, 26/11/2014, punto III. 
y la prescripción de carácter vinculante de las decisiones de la CIDH, todo ello conforme a la jurisprudencia sentada por aquel tribunal y por la CSJN ${ }^{15}$.

Oída la procuradora, se dio la palabra al expresidente D. Carlos Saúl Menem, quien se desvinculó del proceso, ya que —adujo-, "no ha sido parte en el juicio internacional, cuyo pronunciamiento recayó condenando al Estado Argentino, por lo que nada tiene que expresar al respecto» ${ }^{16}$. En sus palabras, estaba aludiendo a un principio constitucional y convencional básico, como es el del debido proceso, y a otro procesal, como es el de su legitimación (Garay, 2017: 2). Así, la Corte entró a conocer, nuevamente, el asunto.

\section{LA DENUNCIA DE FALTA DE PROCESO}

Antes de entrar en el fondo de la resolución de la Corte, es necesario atender la denuncia esgrimida por la procuradora general de la nación. Esta, si bien se encuentra difuminada en el contenido del dictamen, resulta trascendente de cara a futuro.

Teniendo presente que lo que se pretendía era —ni más ni menos-, proceder a la ejecución de sentencias de la $\mathrm{CIDH}$, resulta lógico que exista un canal procesal dentro del Estado argentino por el cual se articule la búsqueda del cumplimiento de las resoluciones de aquella.

Ejecutar sentencias implica, básicamente, dotar de eficacia a una decisión judicial por medio de un camino procesal que obligue al cumplimiento de su contenido. En el caso de las sentencias de la Corte Interamericana de Derechos Humanos, se entiende (por la conjunción de los arts. 67 y 68.1 de la $\mathrm{CADH}$ ), que sus sentencias deben ser cumplidas por el Estado parte con prontitud.

Algunos autores han señalado el gran problema que tienen este tipo de sentencias que vuelven al Estado. Así, se ha dicho que al momento de buscar el cumplimiento e iniciar las reparaciones ordenadas, en muchos Estados parte se ha generado la duda sobre cómo se determina la institución estatal o

15 Sobre esto, se recomienda la lectura de Hitters (2008: 144), quien reseña de manera escalonada las distintas resoluciones adoptadas por la CIDH y por la CSJN que resaltan el carácter obligatorio de las disposiciones contenidas en las sentencias emanadas de la CIDH, en el ámbito interno.

16 Véase Fallos 340: 50 - CSJN: Ministerio de Relaciones Exteriores y Culto s/ informe sentencia dictada en el caso «Fontevecchia y D'Amico vs. Argentina» por la Corte Interamericana de Derecho Humanos, resuelto el 14/02/2017, considerando 5. ${ }^{\circ}$. 
autoridad pública encargada de adoptar lo señalado por la CIDH y cumplir con las víctimas (Miranda Burgos, 2014: 134).

El gran problema es señalar, en el ámbito interno, a quién le corresponde cumplir con la sentencia que se ha dictado, es decir, quién tendrá capacidad jurídica para poder abordar la ejecución de la resolución recaída contra el Estado. Por ello, y conforme a la doctrina sentada por la CIDH, se debería entender que será de exclusiva responsabilidad interna el determinar o adecuar la normativa para el procedimiento y cumplimiento íntegro de la sentencia (Miranda Burgos, 2014: 134).

La procuradora, en el desarrollo de su motivación, indicó, así, que: «[...] la carencia de normas internas que regulen específicamente la ejecución de sentencias de los órganos de protección de los derechos humanos no puede constituirse en un óbice para satisfacer los compromisos internacionales de la República» ${ }^{17}$. Como se aprecia, su postura es clara, al entender que, por más que no exista un canal idóneo dentro del ordenamiento procesal argentino, no puede dejar de ejecutarse el contenido de la resolución.

Por ello, sus palabras expresan una denuncia y un requerimiento al Poder Legislativo para que encare el desafío de otorgar un orden legal al problema que salta a la luz con este asunto. La misma denuncia realiza Abramovich (2017: 23), quien resalta que sería conveniente que el Congreso reactivase el debate y reglamentase el art. 75 inc. 22 de la Constitución, «[...] diseñando mecanismos de ejecución de decisiones internacionales que aseguren la reparación adecuada de las víctimas, y la restitución de sus derechos conculcados».

Sobre lo mentado, la CIDH ya había dicho que «los Estados deben asegurar la implementación a nivel interno de lo dispuesto por el Tribunal en sus decisiones» ${ }^{18}$. Como así también, que "en virtud del carácter definitivo e inapelable de las sentencias de la Corte, según lo establecido en el artículo 67, éstas deben ser cumplidas de manera pronta por el Estado en forma íntegra» ${ }^{19}$.

En la República Argentina, al no existir un procedimiento propio de ejecución de sentencias de la $\mathrm{CIDH}$, se produce un desamparo en el debido proceso al recurrente ganador, por cuanto si bien tiene una condena que lo

17 Véase Fallos 340: 50 - Dictamen de la procuradora general de la nación en el asunto Ministerio de Relaciones Exteriores y Culto s/ informe sentencia dictada en el caso «Fontevecchia y D’Amico vs. Argentina» por la Corte Interamericana de Derecho Humanos, 26/11/2014, punto III.

18 Véase caso Baena, Ricardo y otros vs. Panamá, CIDH, 28/11/2003, párrafo 131.

19 Véase caso Kimel vs. Argentina, supervisión de cumplimiento de sentencia, resolución del 15/11/2010, considerando $4 .^{\circ}$. 
beneficia a nivel interamericano, tiene que volver a sortear —en el ordenamiento interno-, diversos obstáculos para lograr el cumplimiento efectivo.

Si bien el Estado argentino (en el ámbito del Poder Ejecutivo), al recibir una decisión dictada contra este en el espacio interamericano, acciona un procedimiento con las diversas dependencias de derechos humanos a nivel federal, es claro que, cuando no se cumple con esas decisiones, no queda otra opción al recurrente más que volver a acudir a la $\mathrm{CIDH}$ solicitando su cumplimiento. Esta, a través de los informes de seguimiento de las sentencias, realiza denuncias institucionales, pero no puede forzar el cumplimiento a nivel interno.

Por ello, y en consideración a la resolución adoptada por la CSJN, es necesario prestar atención al pedido de la procuradora, de manera tal que no sean palabras que se las lleve el viento, sino una exhortación a los poderes públicos, quienes deberían tomar nota al respecto (Zuppi y Dellutri, 2017: 4).

\section{EL CONTENIDO SUSTANCIAL SUBYACENTE A LA DECISIÓN DE LA CORTE}

\section{APRECIACIONES INICIALES: SIMPLEZA Y TRASCENDENCIA}

Para comenzar, es menester destacar la claridad y simpleza de la redacción de la resolución adoptada por la Corte Suprema. No es una cuestión nimia, teniendo presente el carácter de los pronunciamientos que en su contenido se desarrollan. Esto ha sido resaltado, ya que se ha señalado, por ejemplo, que la decisión es bastante simple para su lectura e interesante en sus decisiones (Luque, 2017: 1).

Por su parte, Gargarella $(2017,1)$, resaltó, además, que «en términos formales, tiene tres virtudes muy destacables, que son su claridad y relativa brevedad, junto con su carácter comprensible (y no, reservado para expertos)». El mismo autor llama la atención en otro aspecto positivo de la resolución, cual es la búsqueda en su razonamiento de argumentos basados en artículos académicos y en figuras políticas o jurídicas valiosas, los que realmente se usan para construir la lógica y no son invocados meramente como «de autoridad».

En lo que respecta a la sustancia que subyace en el interior de los pronunciamientos, es posible resaltar que el Tribunal ha adoptado una serie de definiciones de suma relevancia jurídica y política que trascienden el concreto caso en estudio y manifiestan una clara toma de posición del máximo tribunal argentino en relación al Sistema Interamericano de Derechos Humanos, con importantes novedades y precisiones respecto de la postura que implícita o explícitamente adoptó en anteriores pronunciamientos (Santiago, 2017: 1). 
Estas definiciones que toma la CSJN tienen un efecto de notoria trascendencia para el sistema jurídico argentino, por cuanto vienen a romper con un esquema jurisprudencial sostenido hasta el momento, dando lugar a un nuevo posicionamiento del Tribunal en el escenario institucional del Sistema Interamericano de Derechos Humanos. La sentencia, pone al Estado argentino en un nuevo lugar y se divorcia de los esquemas sentados hasta el momento, de allí su trascendencia.

La decisión al asunto, en su parte dispositiva, es acompañada por cuatro de los cinco magistrados, votando en disidencia el ministro D. Juan Carlos Maqueda y expresando su voto propio el ministro D. Horacio Rosatti.

En lo que respecta a la incidencia que los votos tienen, no es preciso considerar que ha sido una decisión en fallo dividido (Santiago, 2017: 1), por cuanto el papel que un solo voto en disidencia juega en una corte de cinco miembros, poco valor posee más que el de ilustrar una posición distinta al de la mayoría. Quizás, hubiera sido mejor adjetivar a la decisión como «de distintos matices» o "con distintas posturas», más que hablar de una división, la que sí ocurriría si fueran dos votos contra tres, por ejemplo, o un rechazo de tres contra dos.

A diferencia de Santiago, clara es la maestra Gelli (2017: 2), al afirmar que hubo una "mayoría de fundamentos», ya que no solo hubo una porción superior de ministros que votaron en un sentido determinado, sino que lo hicieron bajo un mismo fundamento. Como bien señala Zagrebelsky (2008: 44), lo óptimo hubiera sido la unanimidad, pero el objetivo realista es más bien llegar a una solución que suscite mayor acuerdo, como es el caso.

Sobre la resonancia que ha tenido en la doctrina la resolución de la Corte, digno es destacar algunas voces, por ejemplo, Gargarella (2017), quien ha dicho que «el fallo es muy controvertible y polémico, pero tiene interés y deja traslucir el impacto de las «nuevas voces integrantes de la Corte)»" Junto a ello, ha precisado que los votos se encuentran, en su medida, y parcialmente al menos, equivocados ${ }^{21}$.

20 Al respecto, González (2017: 11), ha referido el impacto que ha tenido sobre la Corte el ministro Rosatti, quien ha llevado al máximo tribunal su postura doctrinal silenciosa y ha atraído a sí a ministros como Highton de Nolasco o Lorenzetti, quienes han modificado sus previas posiciones. Para conocer mejor el pensamiento que el ministro Rosatti sostenía antes de ingresar a la Corte se recomienda leer la obra Tutela judicial de la Supremacía Constitucional de Carlos José Laplacette (2016: 160-161). Allí, el autor trata de resumir los diversos interrogantes que el ministro se realizaba en relación al control de convencionalidad en Argentina.

21 Sobre ello, Gargarella critica el voto mayoritario por su celosa ansiedad en reafirmar su poder frente a la Corte Interamericana (2017: 3). También, por el ahínco con que de- 
Algunos autores han sostenido, también, que esta decisión constituye un fallo cuestionable, por cuanto la Corte habría dado un par de pasos hacia atrás en la posición preponderante que ocupaba en el país en lo relativo al cumplimiento de las disposiciones relativas a los derechos humanos en América Latina (Zuppi y Delutri, 2017: 1; Saba, 2017: 111)22. Se criticó, también, que la Corte ha contradicho el «monismo profundo» que caracterizó los mejores momentos de la historia constitucional argentina (Alegre, 2017: 35); o que existen ciertas deficiencias lógicas que desatan sin más los nudos constitucionales (Furfaro, 2017).

En sintonía, Pizzolo (2017: 10), ha señalado que la sentencia destaca por su vocación de ruptura respecto al pasado. Aún esto, es fundacional en relación a las nuevas relaciones interordinamentales, aunque abandona una tradición y oscurece la reforma constitucional de 1994, que había colocado a Argentina a la vanguardia de una jurisprudencia dinámica y activa en el cumplimiento de las obligaciones internacionales y la tutela de los derechos humanos.

Frente a ello, se han alzado voces que muestran una clara posición a favor del decisorio (Santiago, 2017; Sola, González Tocci y Caminos, 2017; Gelli, 2017) e, incluso, se ha llegado a sostener que los ministros «han refrescado nociones obvias y han puesto las cosas en su lugar» (Garay, 2017: 3).

Para comprender mejor las posturas, será preciso, pues, analizar el contenido de la resolución y los fundamentos usados para construir los distintos votos.

fendió la CSJN su propia supremacía, y por el modo en que — presumiblemente— va a seguir difiriendo autoridad, y avalando la obligatoriedad de las decisiones de la Corte Interamericana, cuando no entren en conflicto con sus propios criterios al respecto (2017: 4).

Sus críticas se dirigen a los distintos votos, entre ellos, el del ministro Rosatti, por cuanto considera que su enfoque complica indebidamente el escenario, al consagrar un «doble principio» de soberanía interpretativa última, que es, por tanto, doblemente equivocado (2017: 4). También, critica el voto del ministro Maqueda, por considerar que se equivoca al asignar a la voz de la CIDH una autoridad fulminante, superior o definitiva, cuando se trata en cambio de un participante privilegiado - pero no predominante ni supremo ni excluyente-, en la conversación en torno a cómo interpretar el sentido o los alcances de un cierto derecho (2017: 5).

22 Hasta el momento, por ejemplo, se había dicho que «la Corte Suprema de Justicia de la Nación ha dado tempranas muestras de permeabilidad ante las obligaciones emergentes del control de convencionalidad, transmitiendo paralelamente un mensaje directo a los jueces inferiores (y a otras autoridades públicas competentes) para que procedan de modo análogo» (Bazán, 2015: 64). 


\section{EL CONTENIDO ESENCIAL}

Quizás, toda la decisión podría ser sintetizada en un punto de los considerandos, el sexto, que expresa el contenido esencial de lo decidido. Allí, la Corte indica que:

Se encuentra fuera de discusión que las sentencias de la Corte Interamericana, dictadas en procesos contenciosos contra el Estado argentino son, en principio, de cumplimiento obligatorio para este (art. 68.1, CADH) (conf. doctrina de Fallos: 327:5668, voto de la jueza Highton de Nolasco, considerando $6^{\circ}$ ). Dicha obligatoriedad, sin embargo, alcanza únicamente a las sentencias dictadas por el tribunal internacional dentro del marco de sus potestades remediales. En efecto, es con ese alcance que el Estado argentino se ha obligado internacionalmente a acatar las decisiones de la Corte Interamericana.

En este párrafo, se ubica una relación lógica de exclusión por cuanto la Corte, si bien admite que es necesario cumplir las sentencias recaídas contra el Estado dictadas por la CIDH, deja abierta la posibilidad a que se pueda realizar un análisis interno, es decir, en el seno del máximo tribunal, sobre si esa decisión ha sido dictada en el marco de las potestades que la Corte Interamericana posee.

La locución adverbial «sin embargo», es una constante lógica de conjunción, que constituye una proposición lógica compuesta, gracias a la cual se puede producir la exclusión de una de las partes del argumento en cuanto se den los supuestos indicados. Es decir, hay un mantenimiento del presupuesto inicial que da lugar al cumplimiento de las sentencias de la $\mathrm{CIDH}$, pero, en los casos en los que se encuentren situaciones jurídicas que impidan la utilización de la regla, sería posible acudir a la excepción.

La Corte, al usar esta conjunción, viene a dejar abierto el espacio de actuación que puede desarrollar hacia adelante, por cuanto podría - gracias a estas dos simples palabras-, aplicar directamente las sentencias de la $\mathrm{CIDH}$ y ordenar su ejecución.

También, si luego de su análisis considerase que la CIDH se ha extralimitado, podría determinar que es preferible el incumplimiento a nivel nacional de lo resuelto. Por ello, al incluir la expresión "en principio», se advierte la intención del máximo tribunal de reservarse cierto grado de autonomía, en caso de discrepancia con los fallos de aquel tribunal supranacional (Zuppi y Dellutri, 2017: 2).

De esta manera, la misma CSJN —en el caso que resuelve—, se pregunta si la orden contenida en la parte resolutiva de una sentencia de la $\mathrm{CIDH}$ ha sido o no dictada dentro del marco de atribuciones de la Convención y, en 
razón de ello, puede ser cumplido por el Tribunal. Frente a su propia interpelación, la Corte es tajante al determinar que la respuesta negativa se impone —en este caso-, por razones que trata de dilucidar en el contenido de los considerandos.

Otra cuestión de fondo - que hay que saber leer entre líneas-, es la relativa a quién tiene la máxima autoridad interpretativa en relación a un caso concreto en el que entran en conflicto la palabra de la CSJN y de la CIDH. Esto, es un resultado explícito del escenario de fragmentación jurídica que ha enterrado la unidad interpretativa, por lo que la Corte argentina va al rescate de la última palabra de la interpretación de normas constitucionales y, también, de las convencionales (Pizzolo, 2017: 5).

\section{LA SUBSIDIARIDAD Y LA DOCTRINA DE LA "CUARTA INSTANCIA»: EL CAMINO AL ESPEJO PROCESAL}

El hecho que los ciudadanos que se encuentran amparados por el Sistema Interamericano puedan acudir al órgano decisorio que este posee, es decir, la Corte Interamericana, no quiere decir que esta sea una "cuarta instancia» para los recurrentes.

La CSJN resalta el carácter subsidiario del Sistema Interamericano y lo destaca constantemente indicando, además, que es coadyuvante y complementario a los sistemas nacionales. Sostiene sus dichos en las decisiones de la misma $\mathrm{CIDH}^{23}$ y en lo enfatizado por la Comisión Interamericana de Derechos Humanos ${ }^{24}$. Es decir, para mantener su posición al respecto, no acude a sus propios razonamientos, sino que se dirige a los asumidos por el órgano que dictó la sentencia que debería cumplir. Por ello, si se asumiese que la CIDH tiene una competencia revisora, se estaría excediendo el carácter coadyuvante y complementario de la jurisdicción internacional (Sola, González Tocci y Caminos, 2017: 3).

Así, la CIDH no es un órgano de apelación o casación, sino un órgano al que los afectados tienen la posibilidad de acudir, pero que no constituye un tribunal posterior necesario al último tribunal nacional, ya que no es una alzada de la CSJN (Sola, González Tocci y Caminos, 2017: 4). Ahora, si bien la $\mathrm{CIDH}$-en su progresividad-, ha actuado como si fuera una cuarta instancia en los hechos (incluso autoridad supraestatal general), no lo ha reconocido en la forma (De Clément, 2009: 68).

23 Véase caso Genie Lacayo, CIDH, 29/01/1997.

24 Véase Comisión Interamericana de Derechos Humanos, Informe 39/96, caso 11.673. Argentina, 15/10/1996, puntos 48 y 51 . 
Por esto, la CSJN insiste en que, si se dejase sin efecto lo resuelto por ella misma en la causa por la cual se acudió a la CIDH, implicaría, per se, transformar a aquel tribunal en una "cuarta instancia» revisora de las sentencias dictadas en su seno. Se produciría, de esta forma, una violación a los principios estructurales del Sistema Interamericano y se excederían las obligaciones convencionalmente asumidas por el Estado argentino cuando ingresó a aquel. Esta situación genera tensiones, que pueden llegar a interrogantes acerca de la calidad suprema que la Constitución argentina asigna a la CSJN (Gelli, 2017: 2).

Hay un punto en el cual la Corte es bastante clara, sobre todo en el asunto que se trae a resolver. Indica que: «Reconocer a la Corte Interamericana tal carácter (el de cuarta instancia) implicaría, por otra parte, la paradoja de que esa instancia revisora hubiera sido ejercida en un proceso que no reconoce continuidad con el desarrollado por esta Corte, al ser diferentes sus elementos fundamentales, tales como las partes y la prueba $»^{25}$.

En el sentido de lo expuesto, por ejemplo, quienes acuden ante la $\mathrm{CIDH}$ son los vencidos, quienes apuntan contra el Estado argentino para que asuma su responsabilidad. En aquel proceso llevado al Sistema Interamericano no formó parte, por ejemplo, el expresidente D. Carlos Saúl Menem, quien había ganado en el ámbito estatal. Cabe recordar que el actual senador nacional bien indicó — cuando se le corrió traslado—, que no podía aportar nada por cuanto no fue sujeto procesal internacional.

La CSJN, en este punto, clarifica muy bien su apartamiento de la decisión de la CIDH, por cuanto garantiza también que los cumplimientos de las decisiones del Tribunal Interamericano se harán, siempre y cuando, exista un espejo procesal en cuanto a las partes que llegaron a última instancia en Argentina y que, ahora, acuden a él.

Esta interpretación de la Corte ha sido criticada por Abramovich (2017: 11), quien ha dicho que:

La fórmula de la cuarta instancia se refiere simplemente a que la Corte Interamericana no revisa el acierto o el error de las decisiones de los tribunales nacionales en la aplicación del derecho nacional si actuaron respetando el debido proceso y se trata de tribunales independientes e imparciales. En virtud de esta regla se limita en ese aspecto el margen de revisión del caso litigioso para que el sistema interamericano sea subsidiario de los sistemas judiciales nacionales.

25 Véase Fallos 340: 50 - CSJN: Ministerio de Relaciones Exteriores y Culto s/ informe sentencia dictada en el caso "Fontevecchia y D'Amico vs. Argentina» por la Corte Interamericana de Derecho Humanos, resuelto el 14/02/2017, considerando 11. ${ }^{\circ}$. 


\section{LA EXTRALIMITACIÓN DE LA CIDH}

La CSJN, en el considerando $6 .^{\circ}$, ya bien decía que analizaría si en el caso en concreto había o no una extralimitación de las facultades de la CIDH. Así lo hace en los considerandos $13 .^{\circ}$ y $14 .^{\circ}$, cuando resalta que el tenor literal del art. 63.1 del pacto de San José de Costa Rica no contempla la posibilidad de que la CIDH disponga que se deje sin efecto una sentencia de sede nacional.

Para tratar de dilucidar su propia comprensión, recae nuevamente en los pronunciamientos de la CIDH e indica que, si bien esta ha considerado este remedio como una forma de reparación, también ha reconocido que en algunos casos es improcedente ${ }^{26}$.

La Corte es, también, bastante consciente de su pronunciamiento, y trata de dejar en claro que comprende y no niega el carácter vinculante de las sentencias de la $\mathrm{CIDH}$, pero que este solo se constituye como tal, cuando se cumple cabalmente con lo establecido en el art. 68.1 de la CADH.

En este sentido, no niega que los pronunciamientos de la CIDH son obligatorios e inapelables para los Estados y que, al hacer el control de convencionalidad, es necesario incluir la jurisprudencia de la Corte por su calidad de intérprete última de la $\mathrm{CADH}$, hecho por el cual se ha llegado a hablar del imperio de la jurisprudencia interamericana en el orden interno (Drnas de Clément, 2009: 51).

\section{LA INTRODUCCIÓN DE LA DOCTRINA DEL MARGEN DE APRECIACIÓN NACIONAL}

La CSJN enfatiza en su entendimiento la existencia de un margen de apreciación nacional que subyace en el mismo fundamento de carácter subsidiario de la $\mathrm{CIDH}^{27}$. Trata, en este sentido, de volcar en Argentina la doctrina desarrollada por el Tribunal Europeo de Derechos Humanos, aunque lo hace no desde arriba hacia abajo (es decir, desde una construcción regional que admite la existencia de un espacio soberano), sino de abajo hacia arriba.

26 Véanse casos Aloboete y otros vs. Surinam, CIDH, 10/09/1993 y Blake vs. Guatemala, CIDH, 22/01/1999.

27 Hasta el momento, Argentina no había invocado esta teoría ante los organismos interamericanos que han tomado intervención en casos que la tenían como sujeto demandado, sino que se había limitado a utilizar la fórmula de la cuarta instancia, persiguiendo la inadmisibilidad del asunto sin entrar en el análisis de fondo y sin llegar a evaluar si correspondía recurrir al margen de apreciación nacional (López Alfonsín, 2017: 555). 
La Corte trata de determinar su espacio de apreciación y su ámbito de aplicación del derecho en su propia decisión, quizás estableciendo un freno ante el avance que cree que realiza la CIDH. Trata, entre líneas, de hacer valer su soberanía legal y mostrar su descontento con una parte de la sentencia que considera no aplicable al Estado argentino.

Como bien indica en la sentencia, la doctrina del margen de apreciación nacional surge en Europa. Se ha dicho de ella que es una técnica de creación jurisprudencial que ha logrado mantener un punto de equilibrio entre dos necesidades. Por un lado, el reconocimiento a nivel europeo de un mínimo común de protección de los derechos reconocidos en el Convenio, desde una interpretación evolutiva del propio tribunal favorecedora en la protección de los derechos y libertades y, por otro, el mantenimiento de la soberanía nacional de los Estados parte, derivado del carácter subsidiario del propio convenio (Sánchez Molina, 2015: 226).

Esta doctrina ha venido siendo mantenida en el viejo continente y, por ella, se está reconociendo que, bajo la concurrencia de determinadas circunstancias, el Tribunal de Estrasburgo puede declarar su conformidad respecto de ciertas actuaciones de los tribunales de los Estados parte aunque no se compadezcan en todo con los derechos del Convenio. Este resultado - aparentemente contradictorio- - se encuentra justificado por la subsidiariedad de los mecanismos internacionales, así como por la necesidad, expuesta anteriormente, de evitar que las resoluciones del TEDH no sean satisfechas (Sánchez Molina, 2015: 226). Así, la doctrina habilita que se llegue a respuestas diferentes en casos similares que se producen en coyunturas político-sociales diferenciadas y con mayores o menores niveles nacionales de igualdad social (Pérez, 2017: 87).

En el ámbito europeo, se ha dicho que es un ingrediente del ejercicio de proporcionalidad que debe desarrollar Estrasburgo, que busca, a instancia de parte o de oficio, reducir el alcance del control europeo en provecho de la decisión de las autoridades nacionales (García Roca, 2017: 121).

Si bien en el marco del Tribunal Europeo de Derechos Humanos esta doctrina, que se constituye en un concepto jurídico indeterminado, ha tenido un desarrollo prolífico y temprano ${ }^{28}$, no ha sido así en el marco del Sistema Interamericano. Se ha dicho, por ello, que su desarrollo en la jurisprudencia americana ha sido menos prolífico, debido a que los primeros casos sustanciados ante la Corte Interamericana planteaban fundamentalmente situaciones relacionadas con el derecho a la vida, la integridad personal, la prohibición de

28 Ya que las primeras sentencias que hablan sobre el tema comenzaron a dictarse en el año 1958. 
la tortura y el ejercicio de la libertad personal; unos derechos que orbitan en torno al núcleo duro del derecho internacional de los derechos humanos y que se encuentran más alejados del ámbito de aplicación de la noción del margen de apreciación nacional (Pascual Vives, 2013: 222).

Se ha criticado la apelación de la Corte a esta doctrina (Arballo, 2017: 547), por cuanto,

es curioso que, dada la búsqueda de una identidad propia, la Corte argentina elije tomar en préstamo una construcción del sistema europeo al que nuestra república es por completo extraño, obviando que en el Sistema Interamericano no existen precedentes de la adscripción a esta doctrina, lo que es habitualmente señalado por los estudiosos en la materia como una de las particularidades que los distinguen.

El margen de apreciación nacional es traído por la Corte para tratar de mostrar el límite que ella misma se impone, es decir, fundamentar por qué no cumplirá con la sentencia dictada contra el Estado argentino, por considerar que los principios del derecho interno son un límite que no pueden avasallarse.

La CSJN sostiene, en sus considerandos, que cumplir con lo resuelto por la CIDH devendría en un palpable desconocimiento de los principios fundamentales del derecho público argentino, lo que derivaría de los arts. 27 y 108 de la Constitución Nacional, por los cuales se establece la pirámide normativa argentina y se determina el carácter de la CSJN como órgano supremo y cabeza del Poder Judicial. En su argumentación, insiste en que el constituyente originario de 1853 — al redactar la Carta Magna-, estableció una esfera de reserva soberana frente a la cual los poderes internacionales tienen un límite ${ }^{29}$.

Basa su argumentación en que, si bien el art. 75 inc. 22 (incorporado a la Constitución en la reforma de 1994), ha sumado al bloque de constitucionalidad diversos instrumentos internacionales de derechos humanos y ha establecido que su contenido no deroga en parte alguna a la primera parte de la Constitución (donde se encuentra el primigenio art. 27), no puede llevar a

29 Esta referencia al art. 27 ha sido criticada por Abramovich (2017: 19), quien ha sostenido que la apelación a este artículo como constituyente de un orden público originario, pone en jaque al bloque de constitucionalidad (que derivaría de la correcta lectura e interrelación de los arts. 27 y 75 inc. 22 de la Constitución). Considera que, de apelarse solo al art. 27, se podría someter cualquier condena internacional a una suerte de exequatur para determinar si se adecua o no a un orden público originario, quitándole fuerza vinculante a aquellas decisiones que no se ajustasen a aquello que se considera como principios propios del orden constitucional interno. 
entender que estos tengan primacía, sino que serán complementarios. Lo que ha realizado, básicamente, es buscar afinar o corregir interpretativamente las expresiones contenidas en el inc. 22 del art. 75 (Gelli, 2017: 3).

Lo dicho, es así ya que al no haberse establecido expresa ni implícitamente la primacía del derecho internacional de los derechos humanos sobre el propio texto constitucional, corresponde afirmar la primacía normativa de este último sobre el primero según los principios de la lógica jurídica más elemental (Santiago, 2017: 7).

Algunos se han preguntado si esta sentencia no es un paso atrás en la construcción monista desarrollada por la CSJN y se está dando lugar, al menos el caso concreto, a una interpretación dualista, superada ya por los Estados. Frente a esto, se señaló, por ejemplo, que, a lo largo de los últimos setenta años, la monolítica soberanía estatal se ha ido disgregando hasta hacerla, finalmente, un conjunto de disposiciones limitadas. Ya el soberano no tiene el poder absoluto cuando ha restringido su soberanía por medio de un tratado, o por un acto unilateral (Zuppi y Dellutri, 2017: 3).

Ante afirmaciones tan contundentes como la señalada precedentemente, es preciso traer a colación que, en Argentina, no ha habido cesión soberana de derechos, por cuanto los organismos de integración no han ido más allá de la intergubernamentalidad. Así, el utilizar como freno la doctrina del margen de apreciación nacional, se está procediendo al reconocimiento de la soberanía en su completitud y es el propio Estado, en este caso, el que recurre al esquema del principio, y no es el Tribunal el que, deferentemente, lo reconoce.

\section{EL VOTO PARTICULAR Y EL DIÁLOGO ENTRE TRIBUNALES}

El ministro D. Horacio Rosatti, si bien firma con la mayoría, lo hace por su propio voto. Llega a la misma conclusión que los otros tres ministros, pero trata de dejar en claro algunas cuestiones que considera relevantes. Se ha dicho de este voto que contiene «la argumentación más exhaustiva y sólida» (Valcarce Ojeda, 2017: 535).

Insiste, en el considerando $4 .^{\circ}$ de su voto, en la necesidad de comprender que la viabilidad del cumplimiento de las sentencias de la $\mathrm{CIDH}$ se tiene que dar analizando la decisión a la luz de las posibilidades que brinda el ordenamiento argentino. Así, considera que hay ciertos obstáculos insalvables en las disposiciones constitucionales que la CSJN no puede dejar de atender y por las cuales debe velar.

Junto a la mayoría, resalta el valor del margen de apreciación nacional, una vez más viéndolo desde abajo hacia arriba, es decir, desde el orden nacional al internacional. Para ello, recurre nuevamente a los arts. 27 y 108 de la Constitución Nacional, pero agrega, además, los arts. 1 y 116 del ordenamiento 
máximo, relativos a la forma de Estado y de gobierno y a las atribuciones de la Corte.

Ahora bien, un elemento a destacar en su voto es que demuestra la necesidad de entender la decisión de la CSJN en un contexto de «diálogo jurisprudencial», que

[...] procure mantener la convergencia decisional entre los órganos con competencias para dirimir conflictos en los ámbitos nacional e internacional, reconociendo a la Corte IDH como último intérprete de la CADH (art. 62, puntos 1 y $3 \mathrm{CADH}$ ) y a la Corte Suprema de Justicia de la Nación como último intérprete de la Constitución Nacional Argentina (arts. 116 y 117 de la Constitución Nacional) [...] $]^{30}$.

Este diálogo entre tribunales es una realidad que viene sosteniendo la doctrina desde hace unos años respecto a las relaciones existentes entre tribunales nacionales e internacionales, que busca el reconocimiento de una comunidad de intérpretes amplia que excede las fronteras soberanas (Saba, 2017: 148). Se ha señalado que suele hablarse de él cuando en el curso de una resolución podemos encontrar una reseña proveniente de un ordenamiento diferente; externo por tanto de aquel en el que la resolución despliega su eficacia (De Vergottini, 2011: 345-346).

La doctrina tiene cabida, sobre todo, cuando existen derechos que son garantizados, de igual modo, por una Constitución a nivel local y por instrumentos internacionales de la misma materia, lo que lleva a una necesaria puesta en contacto entre los diversos intérpretes de una norma aplicable al caso concreto, que tiene cabida en uno y otro sistema (Toader y Safta, 2016: 77).

Lo que el ministro Rosatti sostiene en su voto es la búsqueda, básicamente, de un diálogo cordial, en el que, si bien existen referencias de un sistema internacional a uno nacional, siempre tiene que existir un respeto para entender quién es el auténtico intérprete de la norma a aplicar.

El magistrado comprende un diálogo que representa, sin más, un escenario en el cual hay un locutor que debe hablar cuando se constituye en el intérprete de la norma y un interlocutor que debe oír, respetuosamente, la palabra de quien debe aplicarla. Esto, independientemente de quién tenga más poder a nivel regional o nacional. El parámetro que utiliza el ministro Rosatti es, ni más ni menos, que la capacidad de entendimiento del derecho y la necesidad de oír a quien está en mejores condiciones de comprender su completitud.

30 Véase Fallos 340: 50 - CSJN: Ministerio de Relaciones Exteriores y Culto s/ informe sentencia dictada en el caso "Fontevecchia y D’Amico vs. Argentina» por la Corte Interamericana de Derecho Humanos, resuelto el 14/02/2017, voto particular del ministro Rosatti, considerando 8. ${ }^{\circ}$. 
Por lo expuesto, se ha dicho (en relación al caso mexicano, pero que deviene aplicable al argentino por formar parte del mismo sistema), que este diálogo implica no solo que los tribunales nacionales hagan referencia en sus resoluciones a lo que dicen los tribunales internacionales, sino también que estos miren lo que al interpretar la Constitución y demás normas de origen nacional se está haciendo en cada país, para así estar en vías de construir una jurisprudencia global de derechos humanos (Castilla Juárez, 2009: 187). De esta manera, el diálogo se da dentro del ordenamiento y a nivel internacional tanto de manera horizontal como vertical, ascendente y descendente.

La postura sostenida por el ministro Rosatti viene a fundarse en los desafíos que ha acarreado consigo la implementación del Sistema Interamericano de Derechos Humanos, en el que se ha creado el interesantísimo problema de su articulación y armonización con la protección que también realizan las normas y tribunales nacionales. Todo ello lleva a la necesidad de determinar, más allá de los naturales esfuerzos de armonización y coordinación, a quién le corresponde la supremacía normativa final en los ordenamientos jurídicos de las democracias constitucionales (Santiago, 2017: 4-5).

Este diálogo que se pretende construir debe seguir los parámetros reseñados por Bazán (2015:64), cuando señala, por ejemplo, que las aperturas dialógicas entre los tribunales internos y la CIDH no apuntan a generar una relación de jerarquización formalizada entre esta y aquellos, sino a trazar una vinculación de cooperación en la interpretación pro persona de los derechos fundamentales.

La cuestión de la búsqueda de diálogo ha encontrado algunas voces encontradas, como la de Gargarella (2017: 4), quien duramente señaló que «tomarse en serio el valor del «diálogo entre tribunales debería haber implicado, en este caso, reconocer el valor de lo dicho por la Corte Interamericana en relación al caso "Fontevecchia"». También, Arballo (2017: 553), ha destacado que «la postura dialoguista pondera el ideal de la conversación al tiempo que cierra la puerta tras de sí dando por concluido el tema».

\section{EL VOTO EN DISIDENCIA}

No es posible dejar de atender los fundamentos del voto en disidencia del magistrado D. Juan Carlos Maqueda. Su voto, claramente contrario a los formulados por la mayoría, da cuenta de una continuidad con la doctrina sentada por el Tribunal hasta el momento.

Su argumentación se resume, sin más, en la interpretación que se debe realizar, después de 1994, del art. 75 inc. 22 de la Constitución Nacional. Así, señala que: «[...] las sentencias de la Corte Interamericana de Derechos Humanos pronunciadas en causas en las que el Estado argentino sea parte 
deben ser cumplidas por los poderes constituidos en el ámbito de su competencia y, en consecuencia, son obligatorias para la Corte Suprema de Justicia de la Nación $»^{31}$.

De esta manera, ante una resolución dictada por la CIDH que establezca un mandato de recibo para la CSJN, esta no debe más que cumplir y ejecutar el pronunciamiento realizado. Existe, por ende, un deber de acatamiento de las decisiones, que no sería más que dar cabida a un principio básico del derecho sobre la responsabilidad internacional del Estado.

Argentina, así, está obligada a acatar los deberes convencionales internacionales de buena fe (pacta sunt servanda), de conformidad a lo dispuesto por la Convención de Viena sobre el Derecho de los Tratados de 1969.

En su voto en disidencia, el magistrado busca cumplir con lo dispuesto por la $\mathrm{CIDH}$, en especial en lo atinente a dejar sin efecto los fallos dictados por la Corte Suprema y la Cámara Nacional de Apelaciones en lo Civil, Sala H.

Su decisión, nuevamente, es acompañada por algún sector de la doctrina, que ha dicho, por ejemplo, que es destacable la posición asumida por el ministro Maqueda, que correctamente disintió con la mayoría, y opinó resolver esta causa como solo podía hacerse declarando sin efecto los fallos cuestionados (Zuppi y Dellutri, 2017: 4), o que el voto del ministro es la doctrina hoy mayoritaria en la República Argentina (Luque, 2017: 2).

\section{CONCLUSIONES}

Para empezar, tal cual lo hizo la CSJN, es necesario adelantar la posición de esta tribuna, para la cual, la decisión adoptada en relación al asunto llevado a la Corte ha sido totalmente acertada.

Es acertada, por cuanto logra una serie de cometidos que dan cuenta de un cambio de parecer en una nueva composición de la Corte, que ha traído aires de renovación y de adopción de decisiones que bregan por sostener la eficacia del factor soberanía y sus diversas interacciones en el marco del sistema de protección interamericano.

La CSJN, en esta causa, no deja abierta la puerta a una desprotección de los derechos humanos (como algunos han señalado), sino que más bien aporta, desde su seno, una llamada de atención a la misma CIDH en relación

31 Véase Fallos 340: 50 - CSJN: Ministerio de Relaciones Exteriores y Culto s/ informe sentencia dictada en el caso "Fontevecchia y D’Amico vs. Argentina» por la Corte Interamericana de Derecho Humanos, resuelto el 14/02/2017, voto en disidencia del ministro Maqueda, considerando 2. ${ }^{\circ}$ 
a la necesidad de escucha y diálogo, de adopción de medidas dentro de las competencias propias y de reconocimiento de la existencia en el Sistema de diversos Estados que tienen un entramado constitucional que no es posible dejar de advertir.

La decisión trae consigo la apertura a un cambio de paradigma, pero no un corte en las relaciones entre los dos órganos, por cuanto bien deja en claro que comprende la obligatoriedad de las sentencias, pero busca al mismo tiempo concienciar acerca de la necesidad del respeto y sujeción a las normas que gobiernan cada sistema.

Esta resolución, introduce en el seno del ordenamiento argentino dos conceptos que vienen desde hace años trabajándose en otros ámbitos jurisdiccionales (como el europeo): la doctrina del margen de apreciación nacional y el diálogo entre tribunales. Se realiza una interpretación interna de estos, apreciando que existen ciertos principios constitucionales propios del derecho público argentino que son necesarios atender y respetar y, además, señalando que es ineludible la atención de la interpretación al propio ámbito de actuación. Que no se hayan seguido los mismos canales que en el sistema europeo para la consecución de este propósito, no le quita valor al objetivo de la Corte, que lícitamente ha buscado su introducción desde abajo hacia arriba.

No es posible considerar que la decisión de la Corte se haya traspasado en sus competencias o haya querido ir más allá de lo posible; por el contrario, ha entendido perfectamente su rol en el Sistema Interamericano y ha colaborado, con su palabra, a la construcción de un nuevo diálogo entre este tribunal y la CIDH.

El diálogo que se reclama se encuentra abierto, por cuanto habrá que esperar al nuevo informe de seguimiento de la sentencia en juego, para saber cuál será la postura que adoptará la $\mathrm{CIDH}$, la que podrá aceptar lo pronunciado por la CSJN o, por el contrario, continuar exigiendo su cumplimiento.

Esta nueva etapa se basa en la comprensión que el Sistema no responde a un ámbito de supraestatalidad - como algunos autores que han sido reseñados en este trabajo erróneamente piensan-, ya que no hay ninguna cesión soberana al Sistema Interamericano, sino que, por el contrario, este se constituye en un elemento supletorio, que no debe cercenar la real soberanía, que reside en el Estado.

Es esperable, después de esta decisión, que haya dos acuses de recibo. El primero, por parte del legislador argentino, que debe tomar nota del pedido de una reglamentación que ayude a la ejecución de las sentencias recaídas en contra del país en sede interamericana. El segundo, el de la misma $\mathrm{CIDH}$, que debería escuchar esta exhortación realizada con forma de decisión por parte de la CSJN que no es, ni más ni menos, que la suprema intérprete del ordenamiento aplicable en el país. 


\section{Bibliografía}

Abramovich, V. (2017). Comentarios sobre «Fontevecchia», la autoridad de las sentencias de la Corte Interamericana y los principios de derecho público argentino. Pensar en Derecho, 10, 9-25.

Alegre, M. (2017). Monismo en serio: «Fontevecchia» y el argumento democrático. Pensar en Derecho, 10, 27-35.

Arballo, G. (2017). Los Tratados de Derechos Humanos frente a la Constitución Nacional en una nueva (y problemática) jurisprudencia de la Corte Argentina. Revista de Derecho Público Rubinzal-Culzoni, 1, 546-553.

Bazán, V. (2015). El control de convencionalidad como instrumento para proteger derechos esenciales y prevenir la responsabilidad internacional del Estado. Anuario Iberoamericano de Justicia Constitucional, 19, 25-70. Disponible en: https://doi. org/10.18042/cepc/aijc.19.02.

Castilla Juárez, K. (2009). Los primeros pasos para la construcción del diálogo jurisprudencial en materia de derechos humanos: Tribunales nacionales-tribunales internacionales. Reforma Judicial, Revista Mexicana de Justicia, 14, 165-187.

De Clément, Z. D. (2009). Corte Interamericana de Derechos Humanos ¿Cuarta Instancia? Academia Nacional de Derecho y Ciencias Sociales de Córdoba. Disponible en: http://www.acaderc.org.ar/doctrina/articulos/corte-interamericana-de-derechos-humanos-bfcuarta.

De Vergottini, G. (2011). El diálogo entre Tribunales. Teoría y Realidad Constitucional, 28, 335-352.

Furfaro, L. (2017). Las ataduras de Ulises se aflojan: el pronunciamiento de la CSJN frente al caso «Fontevecchia» de la Corte IDH. Pensar en Derecho, 10, 37-79.

Garay, A. F. (2017). En ocasiones necesitamos educarnos en lo obvio. Diario La Ley Argentina, 23/02/2017, 2, La Ley Online AR/DOC/500/2017.

García Roca, J. (2007). La muy discrecional doctrina del margen de apreciación nacional según el Tribunal Europeo de Derechos Humanos: soberanía e integración. Teoría y Realidad Constitucional, 20, 117-143.

Gargarella, R. (2017). La autoridad democrática frente a las decisiones de la Corte Interamericana. Diario La Ley Argentina, 23/02/2017, 3, La Ley Online AR/ DOC/497/2017.

Gelli, M. A. (2017). Los alcances de la obligatoriedad de los fallos de la Corte Interamericana y la reivindicación simbólica de la Corte argentina. Diario La Ley Argentina, 23/02/2017, 5, La Ley Online AR/DOC/500/2017.

González, S. A. (2017). La posición solitaria que se volvió mayoría en la Corte. A propósito del «Caso Fontevecchia». Microjuris, MJ-DOC-10665-AR / MJD10665.

Hitters, J. C. (2008). ¿ Son vinculantes los pronunciamientos de la Comisión y de la Corte Interamericana de Derechos Humanos? (Control de constitucionalidad y convencionalidad). Revista Iberoamericana de Derecho Procesal Constitucional, 10, 131-156.

Laplacette, C. J. (2016). Tutela judicial de la supremacía constitucional. Anatomía del control de constitucionalidad difuso. Buenos Aires: Euros Editores y Montevideo: B de F. 
López Alfonsín, M. A. (2017). El estreno de la doctrina del margen de apreciación nacional en la jurisprudencia argentina. Revista de Derecho Público Rubinzal-Culzoni, 1, 555-566.

Luque, C. (2017). ¿Convencionalismo, no convencionalismo o ultra-convencionalismo? Buscando un poco de sensatez constitucional. Diario Constitucional y Derechos Humanos, 149. Disponible en: https://dpicuantico.com/sitio/wp-content/ uploads/2017/02/COLUMNA.pdf.

Miranda Burgos, M. J. (2014). La ejecución de sentencias de la Corte Interamericana de Derechos Humanos en el ordenamiento jurídico interno. Revista del Instituto Interamericano de Derechos Humanos, 60, 129-156.

Pascual Vives, F. J. (2013). El margen de apreciación nacional en los tribunales regionales de derechos humanos: una aproximación consensualista. Anuario Español de Derecho Internacional, 29, 217-262.

Pérez, A. (2017). Una mirada desde América Latina sobre el margen de apreciación estatal en el Tribunal Europeo de Derechos Humanos: ¿génesis de una permanente tensión entre democracia y derechos? Revista Jurídica de la Universidad de Palermo, 15 (1), 75-94.

Pizzolo, C. (2017). ¿Ser «intérprete supremo» en una comunidad de intérpretes finales? De vuelta sobre una interpretación «creacionista» de los derechos humanos. Diario La Ley Argentina, 23/02/2017, 7, La Ley Online AR/DOC/501/2017.

Saba, R. P. (2017). No huir de los tratados. Pensar en Derecho, 10, 111-161.

Sánchez Molina, P. (2015). Margen de apreciación nacional (en los sistemas de protección internacional de los derechos humanos). Eunomia, Revista en Cultura de la Legalidad, 9, 224-231.

Santiago, A. (2017). ¿Desobediencia debida? ¿Quién tiene la última palabra? Diario La Ley Argentina, 23/02/2017, 13, La Ley Online AR/DOC/493/2017.

Sola, J. V., González Tocci, L. y Caminos, P. A. (2017). La Corte Suprema y la Corte Interamericana. Diario La Ley Argentina, 23/02/2017, 20, La Ley Online AR/ DOC/504/2017.

Toader, T. y Safta, M. (2016). The Dialogue of Constitutional Judges. Frankfurt am Main: Peter Lang GmbH.

Valcarce Ojeda, G. (2017). Algunas consideraciones acerca del fallo «Ministerio de Relaciones Exteriores y Culto s/ informe sentencia dictada en el caso 'Fontevecchia y D’Amico vs. Argentina' por la Corte Interamericana de Derechos Humanos». Revista de Derecho Público Rubinzal-Culzoni, 1, 527-545.

Zagrebelsky, G. (2008). Principios y votos. El Tribunal Constitucional y la política. Madrid: Mínima Trotta.

Zuppi, A. L. y Dellutri, R. (2017). Comentario a un diálogo entre quienes no se escuchan. La decisión de la Corte Suprema en el caso «Fontevecchia y D’Amico c. República Argentina. Diario La Ley Argentina, 23/02/2017, 13, La Ley Online AR/ DOC/505/2017. 